\title{
Microstructuring of joining areas in aluminium alloy sheets by Jet Electrochemical Machining
}

\author{
René Schimmelpfennig1), Matthias Hackert-Oschätzchen ${ }^{1}$, André Martin ${ }^{1}$, Andreas Schubert ${ }^{1}$ \\ 1) Professorship Micromanufacturing Technology, Chemnitz University of Technology, Chemnitz, \\ Germany, rene.schimmelpfennig@mb.tu-chemnitz.de
}

\section{Keywords}

Aluminium Alloy, Fibre-Reinforced Thermoplastics, Jet Electrochemical Machining, Microstructuring, Ultrasonic Vibration-Assisted Joining

\begin{abstract}
In this work, we show how to increase tensile shear strength by means of microstructuring the metallic part for ultrasonic vibration assisted joining of hybrid compounds. The aluminium alloy EN AW-5083 and a carbon fibre-reinforced plastic (CFRP) from Bond Laminates are used as a material combination. A suitable method is electrochemical processing $(E C M)$. The microstructuring is carried out with continuous electrolyte-free jet machining (Jet-ECM). A special characteristic of this technology is the restriction of electric current to a limited area of the electrolyte jet. After describing the materials and sample geometry used, the Jet-ECM technology and the ultrasonic vibration-assisted joining process are explained. The strength of the joint is assessed by means of a tensile shear test. The determined results of the tensile shear strength for hybrid connections between microstructured aluminium sheets and CFRP are compared to those of unstructured aluminium sheets. Furthermore, the influence of the microstructure on the tensile shear strength achieved is discussed using metallographic cross-sections of the joining area.
\end{abstract}

\section{Introduction}

The combination of different materials for the production of complex structures is an often-applied approach in lightweight construction. Creating load-bearing joints between such different materials is challenging, for example in the material combination of fibre-reinforced thermoplastics (FRP) and metallic materials like aluminium alloys. A suitable process for the production of such joints is ultrasonic vibration-assisted joining. Therefore, a defined microstructuring of the metallic substrate surface can be applied to increase the achievable tensile shear strength of the produced joints. Microstructuring of joining areas in aluminium alloys using Jet Electrochemical Machining (Jet-ECM) is an applicative process for this task. Electrochemical machining is a technology for high-precision manufacturing of microstructured surfaces based on the principle of anodic dissolution. Main advantages are the machining of metallic workpieces without thermal or mechanical impact as well as the independence from the material's hardness [1]. In addition, burr-free microstructures can be created. This study shows results of experiments, which were performed to quantify the influence of the microstructured joining area on the achievable tensile shear strength of ultrasonic vibration-assisted joints.

\section{Materials and methods}

\subsection{Materials and specimen geometry}

The production of hybrid compounds made of a metallic material and fibre-reinforced thermoplastics was implemented with the aluminium alloy EN AW-5083 (rolled sheet) and a carbon fibre-reinforced thermoplastic polyurethane. The specimen geometry of the aluminium alloy EN AW-5083 is shown in 
Figure 1 with indication of the microstructured joining area. Tepex® Dynalite 208-C200 (4) consolidated composite laminates were used as a fibre-reinforced thermoplastic. This material consists of 4 layers of carbon fibre fabric in $2 / 2$ twill weave, the fibre content is $45 \%$. Thermoplastic polyurethane with a melting temperature $\mathrm{T}_{\mathrm{m}}$ of $190{ }^{\circ} \mathrm{C}$ was used as matrix material. For both materials, sheets with a thickness of $1 \mathrm{~mm}$ were used. The width of the FRP samples was $30 \mathrm{~mm}$. The hybrid compound was produced in the form of an overlap joint. In order to enable a better adhesive bonding of the thermoplastic and an integration of the load-bearing fibres, a microstructure was produced in the area of the joining zone by means of Jet-ECM. The microstructure consists of linear shaped ablations that have a width of approximately $250 \mu \mathrm{m}$ and a distance of approximately $500 \mu \mathrm{m}$. The ablation depth is about $150 \mu \mathrm{m}$. This microstructure consists of 25 horizontal and vertical ablations, resulting in an array of 576 square pins. By the production of the microstructured joining area a $30 \%$ increase in the total surface area could be achieved.

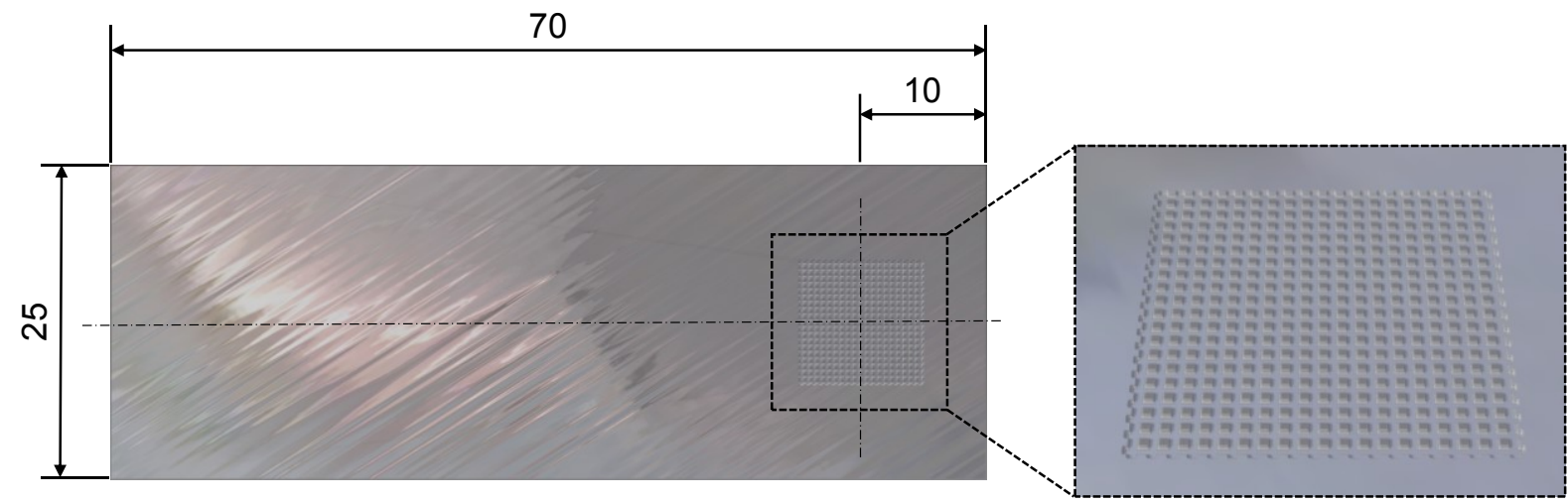

Figure 1: 3D model of the specimen geometry of the aluminium alloy EN AW-5083 with indication of the microstructured joining area $(10 \times 10) \mathrm{mm}^{2}$

Figure 2 shows a detail of the microstructured area produced by Jet-ECM in EN AW-5083. A 3D laser scanning microscope Keyence VK-9700 was used to record the surface texture. The image on the left shows the microstructure as a true colour image, while the height data are shown on the right. One can see that by means of the used ablation method, a burr-free surface could be created. Furthermore, areas with intersecting horizontal and vertical ablation show a higher ablation depth. Jet-ECM was used as a structuring process to reduce a possible susceptibility to cracking at the transition section between the groove base and the plateau edge by generating rounded flank angles. Likewise, a thermal influence on the aluminium sample can be ruled out due to the selected process for microstructuring.
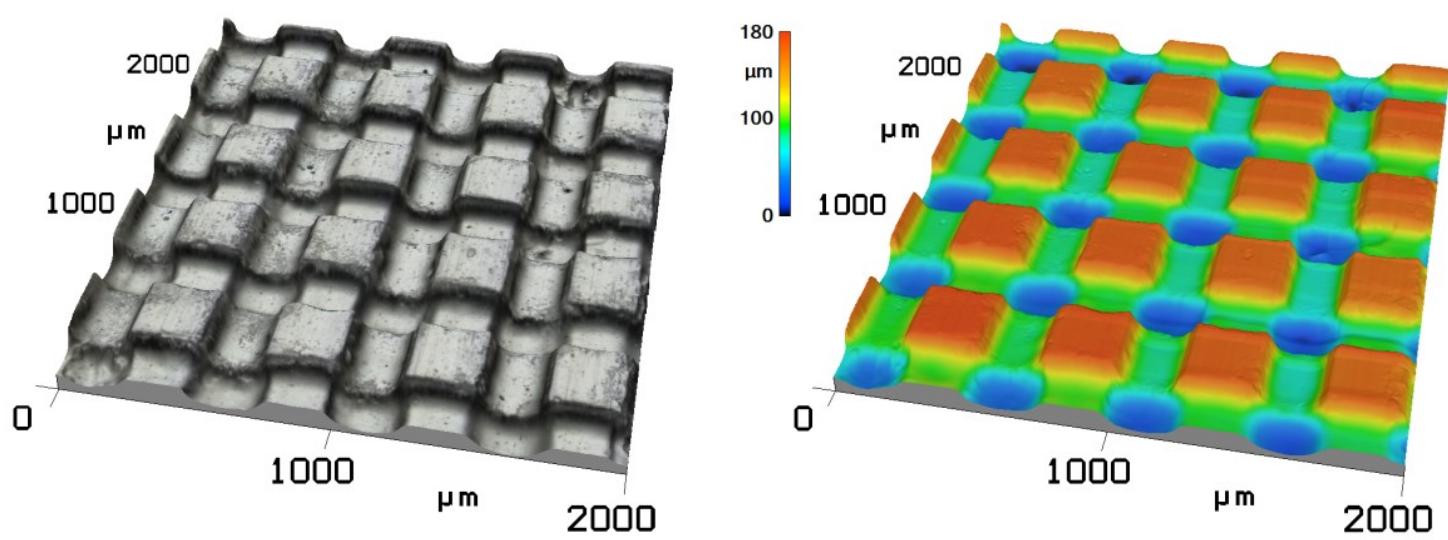

Figure 2: 3D laser scanning microscope images of real surface of the joining area; Colour image (on the left); Image with indication of height values (on the right) 


\subsection{Jet Electrochemical Machining}

Anodic dissolution of metallic workpieces under the influence of electric charge transport is the fundamental principle of electrochemical machining [1],[2],[3]. The dissolution takes places at the interface between the workpiece and an aqueous ion conductor, the electrolyte. By using an aqueous $\mathrm{pH}$-neutral electrolyte, an anodic dissolution process takes place in the area of the free jet. Corrosive changes of the metallic substrate as well as changes of the surface chemistry can be prevented as far as possible. Likewise, grain boundary effects have a minor impact for the chosen combination of EN AW-5083 and the electrolyte. In Jet-ECM, the electrolyte is pumped through a small nozzle supplying direct electric current between the anodic workpiece and the cathodic tool, as shown in Figure 3 . The mean velocity of ejecting is about $20 \mathrm{~m} / \mathrm{s}$ and in interaction of electrolyte and ambient medium air, the liquid forms a free jet. To assure a continuous supply of fresh electrolyte without pressure fluctuation a pulsation free pump is used [2]. As shown in Figure 3 the electrolyte hits the surface of the workpiece in a right angle and hence flows off evenly to all directions of the horizontal workpiece surface.

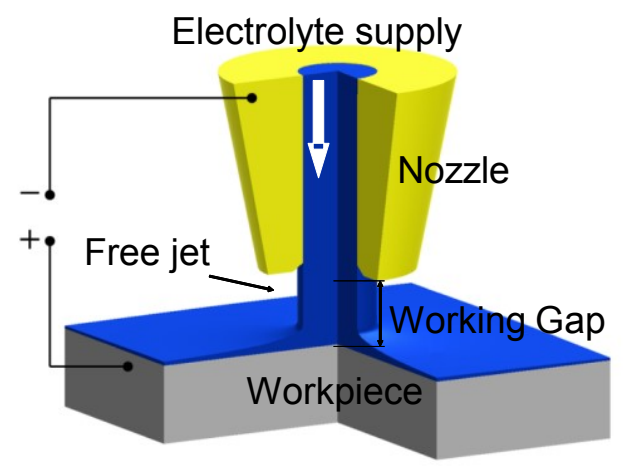

Figure 3: Scheme of Jet-ECM [1]

The parameters used for microstructuring the joining areas by Jet Electrochemical Machining are summarised in Table 1. For the selected microstructure, processing speeds of about $1 \mathrm{~h} / \mathrm{cm}^{2}$ could be achieved when using one single nozzle. In comparison to other ablation or cutting processes, e.g. laser ablation or milling, the processing times are considerably higher. When using several nozzles, the processing time can be reduced by the parallelisation of the removal process. In principle, when using Jet-ECM, structural geometries similar to those created by milling are possible. Because of the anodic dissolution process, there is always edge rounding and thus no sharp corners or burrs are produced.

Table 1: Machining parameters for Jet-ECM of aluminium alloy EN AW-5083

\begin{tabular}{ll}
\hline Parameter & Value \\
\hline Electrolyte & $14,5 \% \mathrm{NaCl}$ solution \\
Voltage & $60 \mathrm{~V}$ \\
Working gap & $100 \mu \mathrm{m}$ \\
Nozzle diameter & $100 \mu \mathrm{m}$ \\
Traversing speed & $200 \mu \mathrm{m} / \mathrm{s}$ \\
\hline
\end{tabular}

\subsection{Ultrasonic vibration-assisted joining}

According to DIN EN ISO 4063 ultrasonic joining is a pressure welding process. The bond formation occurs because of static joining force and a superimposed ultrasonic vibration. Current applications in ultrasonic joining either use the vibration in parallel or in orthogonal direction in relation to the workpiece surface. For the present study, a commercial ultrasonic spot joining system with parallel vibration direction was used. The general structure of such an ultrasonic joining system is shown in Figure 4. 
An ultrasonic joining system mainly consists of an ultrasonic generator, a piezoelectric converter, a booster and the actual joining tool, the sonotrode.

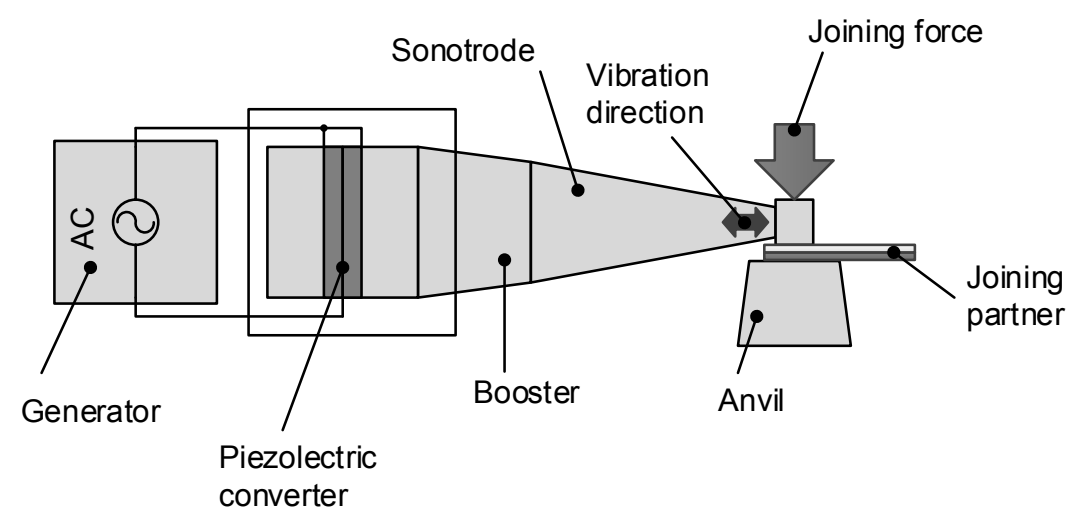

Figure 4: Scheme of an ultrasonic joining system, joining force acting in perpendicular direction to the vibration [4]

The generator converts the input voltage from $50 \mathrm{~Hz}$ into a high-frequency alternating voltage of $20 \mathrm{kHz}$. The converter transforms the electrical oscillation into a mechanical oscillation with the same frequency. With an appropriate design of booster and sonotrode, the necessary displacement amplitude in the joining area is ensured. During the joining process, the parts to be joined are pressed together by a static joining force, extending perpendicularly to the joining zone. Both, the ultrasonic joining with an orthogonal vibration direction [5] as well as the ultrasonic joining with a parallel vibration direction [6] are suitable for the joining of thermoplastic polymers with metals. In addition, it could be shown that using the metal ultrasonic welding, better results are achievable during the joining of fibre-reinforced thermoplastic polymers with metals. It has been shown that the longitudinal vibrations introduced and the associated pulsating compression load cause damage to the reinforcing fibres during ultrasonic joining with an orthogonal vibration direction [7]. Furthermore, it was shown that when using ultrasonic joining with a parallel vibration direction, about half of the energy is required in order to achieve an increase in bond strength of more than $100 \%$ at significantly lower welding time results [6]. The most important joining parameters are the amplitude, the joining pressure and the joining energy. The experiments were performed on a standard spot welding system of the company Branson, type Ultraweld L20, as shown in Fig. 4. In the case of the welding system used, the amplitude is in the range of $5 \mu \mathrm{m}-60 \mu \mathrm{m}$, the pressure can be adjusted between 0,5 bar and $5,5 \mathrm{bar}$, the maximum power output is $4000 \mathrm{~W}$.

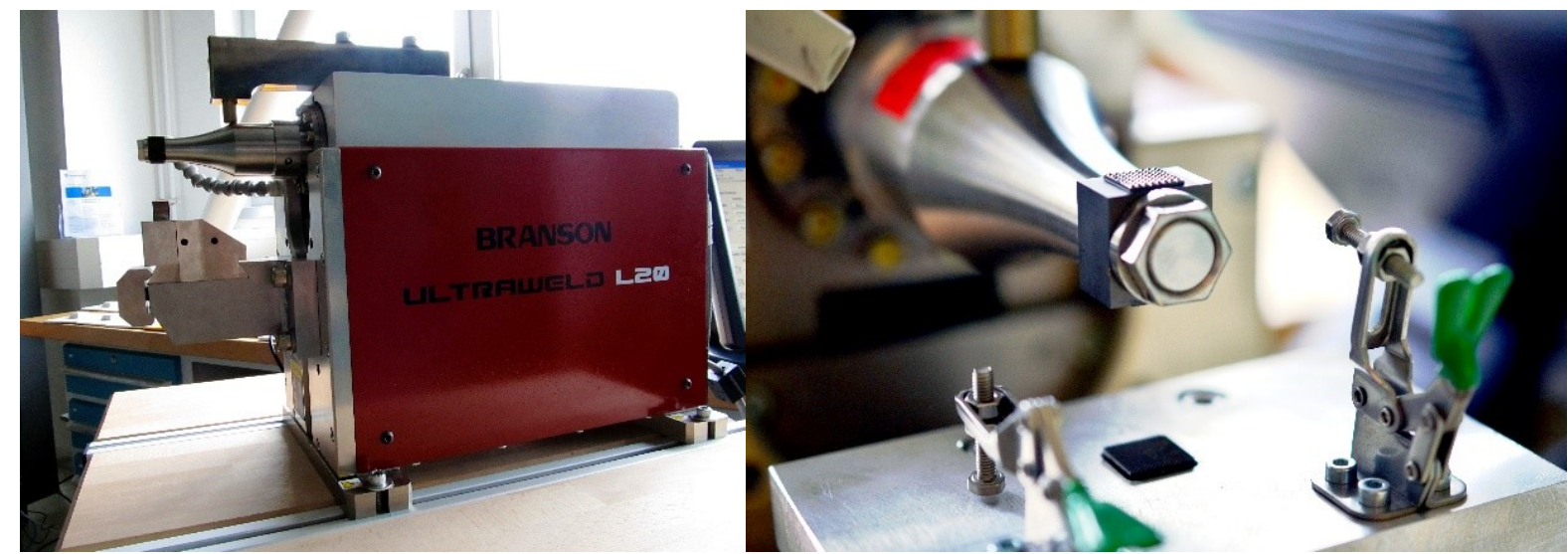

Figure 5: Ultrasonic joining system Branson Ultraweld L20, on the left: actuator unit, on the right: detail of sonotrode with sample fixture 
The aluminium alloy and the carbon fibre-reinforced polymer CFRP were joined as an overlap joint with an overlap length of $20 \mathrm{~mm}$. For the removal of residues on the sample surface, both CFRP and aluminium alloy samples were cleaned with ethanol and dried with compressed air. Subsequently, the samples were inserted and aligned into the joining system. The CFRP was placed on the anvil side and the aluminium sample was arranged on the sonotrode side. Sheet metal strips compensated the resulting height offset between the aluminium sample and the machine table. After placing and aligning the sample, the hybrid joint was created using ultrasonic joining. Initial values for the machine parameters had been determined in previous investigations [8]. The applied joining force acting on the joining area was regulated indirectly by adjusting the pressure in the working cylinder. This pressure was kept at a constant value of 4 bar for all tests.

\section{Results}

\subsection{Microscopic investigation}

For a better understanding of the bonding mechanism, metallographic sections were prepared and reviewed by light microscopy. The sections were prepared transversely to the microstructured area, shown in Figure 6.

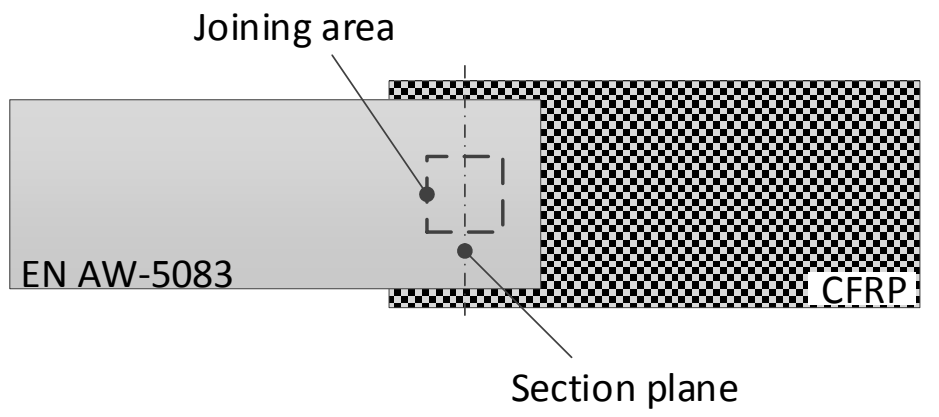

Figure 6: Alignment of metallographic sections in samples

A first overview of the prepared cross sections is shown in Figure 7. The aluminium alloy with microstructures, the individual layers of the CFRP and the embedding agent are visible. The individual layers of the carbon fibre fabric either extend in-plane to the grooves produced by Jet-ECM or out-ofplane.

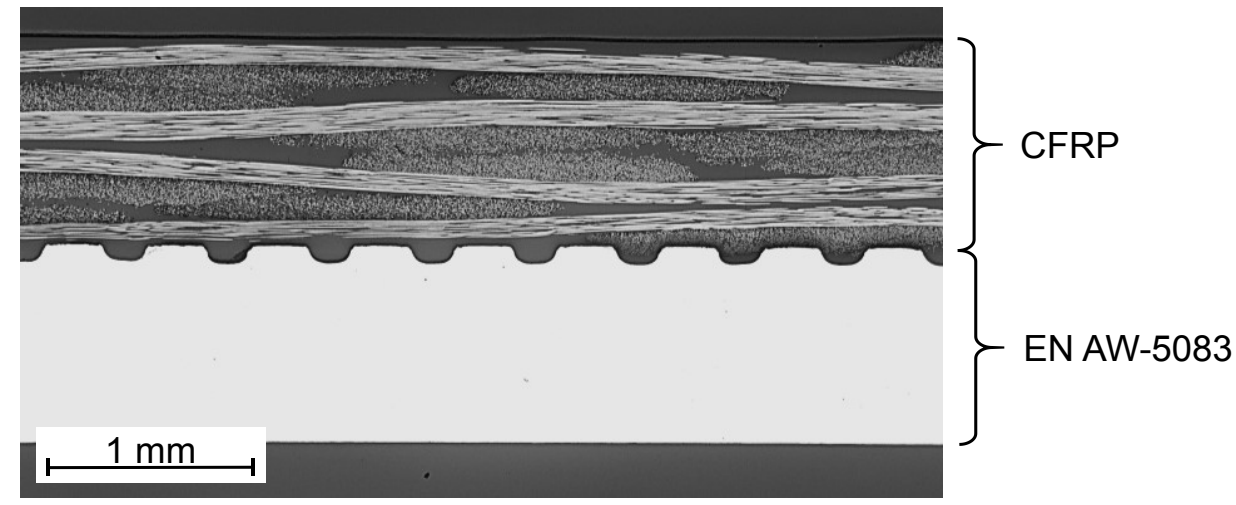

Figure 7: Metallographic cross-sections of the produced EN AW-5083-CFRP hybrid compounds 
One can see in Figure 8 (on the right) that in areas where the fibre direction is parallel to the direction of the microstructures, the CFRP is connected both via the adhesive effect of the matrix material and a form closure as well as via the reinforcing fibres. While in areas (Figure 8, on the left) where the reinforcing fibres are perpendicular to the direction of the microstructure, the CFRP is joined via the adhesive effect of the matrix material and the formation of a form closure between microstructure and matrix without involvement of the reinforcing fibres.
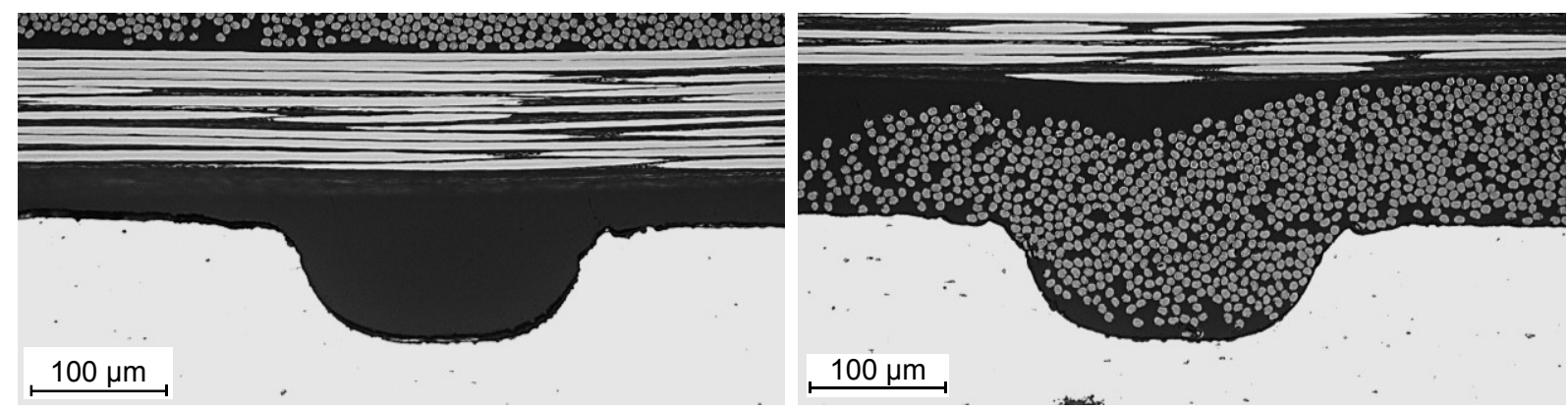

Figure 8: Cross-section details showing different states of the joint depending on the orientation of the reinforcing fibre and the microstructure, fibres perpendicular (on the left); fibres parallel (on the right) to the direction of the microstructure

Due to the geometric structure of the carbon fibre fabric (2/2 twill bond) and the regularly recurring microstructures, these areas alternate constantly. So that areas where bonding is formed by adhesion and form closure with or without an involvement of the reinforcing fibres alternate.

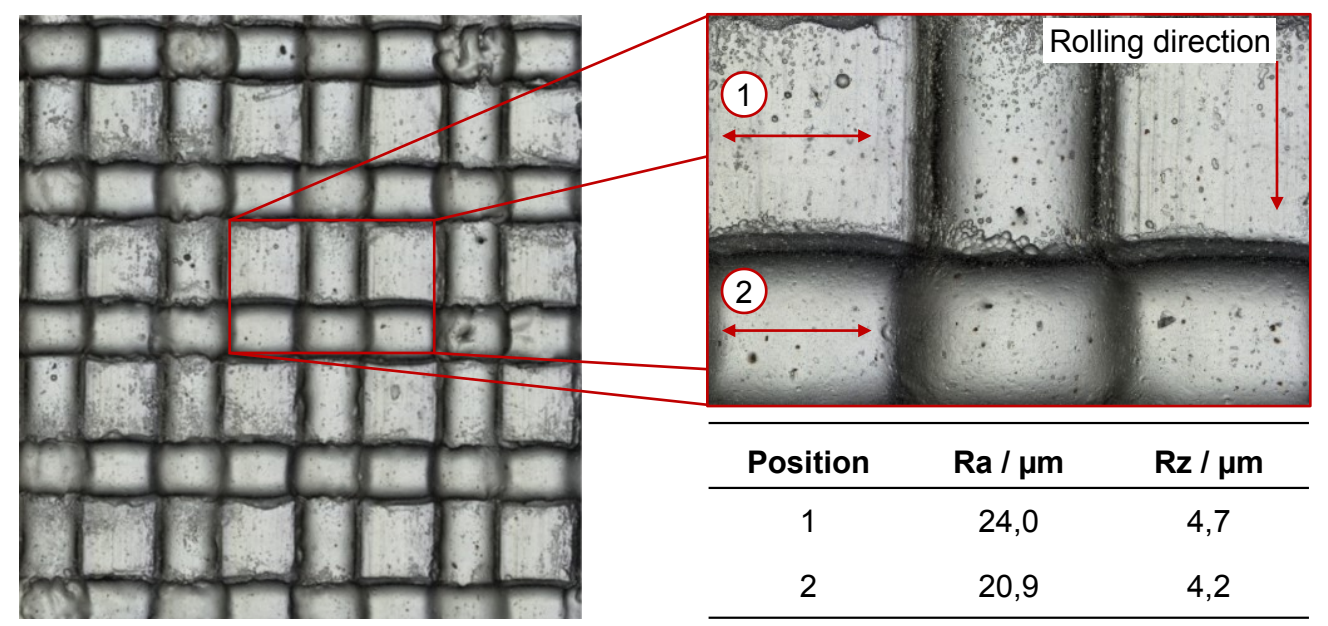

Figure 9: 3D laser scanning microscope images of the microstructured joining area with the average roughness $R a$ and the arithmetic mean roughness $R z$ for an unmachined and a machined surface

Due to the used Jet-ECM method and the associated anodic dissolution of the metal substrate the surface roughness decreases. Figure 9 shows a detailed view of the joining zone with indication of the respective roughness. Position 1 is the initial state of the rolled aluminium sheet, and position 2 is the state after jet ECM machining. The roughness is reduced by about $10-20 \%$ and thus slightly reduces the adhesive content of the total strength, since an increase in roughness is usually accompanied by an increase in the overall joint strength [8]. 


\subsection{Welding results}

After carrying out joining tests, the produced compounds were subjected to a tensile shear load and the maximum force until fracture of the sample was determined. Those tests were carried out on a universal testing machine Zwick Z050 in accordance with DIN EN 1465, with a test speed of $10 \mathrm{~mm} / \mathrm{min}$. Figure 10 shows a typical load-extension diagram and a tensile shear strength diagram of the ultrasonic joined hybrid joint. The load increases continuously until a spontaneous failure occurs. As can be seen from the load-extension diagram, more than twice the force is required to break the joint with a microstructured joining zone. The maximum value for the breaking force increases from $478 \mathrm{~N}$ to $1178 \mathrm{~N}$. No influence is attributable to the attainable extension until the occurrence of the fracture. For hybrid joints with a microstructured metallic joining partner an average tensile shear strength of 10.7 $\mathrm{MPa}$ is obtained. In comparison to aluminium samples in the initial state (rolled sheet) with an average tensile shear strength of $4.2 \mathrm{MPa}$, a reduction of the deviations from $\pm 27 \%$ to $\pm 13 \%$ for the microstructured geometry can be achieved. The tensile shear strengths indicated here refer to a total joining area of $100 \mathrm{~mm}^{2}$. The stress in the tensile shear test leads to a complex stress state in the area of the joint. The failure of the joint mainly results from a failure of the adhesive bond between the matrix and the metal surface and a cohesive matrix failure. With other methods of microstructuring, comparable or higher tensile shear strengths can be achieved. The tensile shear strengths achieved by Jet-ECM are slightly higher than for example for ground surfaces and slightly lower than surfaces with an applied thermal spray layer [8]. However, by applying a spray layer, thermal stress can be introduced into the sheet which leads to a deformation of the sheet.
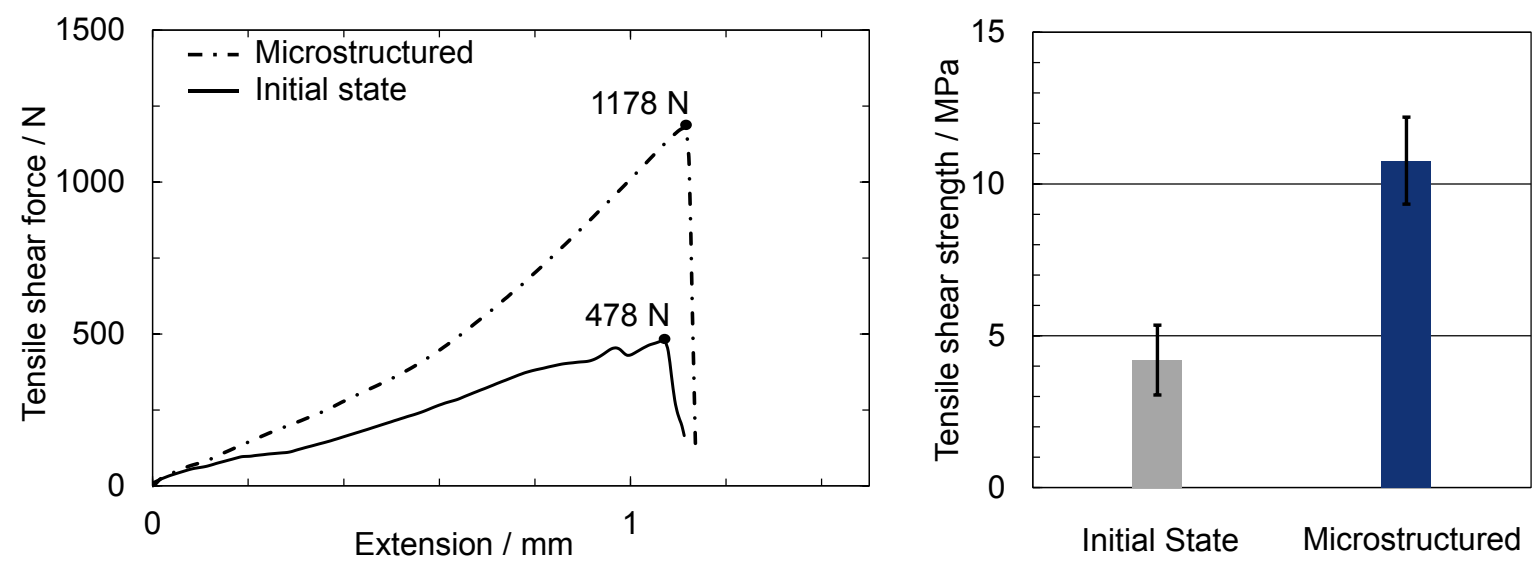

Figure 10: Load-extension diagram of an ultrasonic vibration-assisted joined EN AW-5083 / CFRP joint (on the left); comparison of the achievable tensile shear load for hybrid joints with an unstructured and a structured aluminium joining partner (on the right)

\subsection{Demonstrational geometry}

Based on the results of the lab scale investigations a demonstrational geometry was joined. For this purpose, the hinge of a car bonnet, which usually requires a screw connection, was used. The bonnet hinge was made of the aluminium alloy EN AW-6082 and the microstructure used for the experiments was transferred. Subsequently a joint was created between the fibre-reinforced thermoplastic Tepex ${ }^{\circledR}$ Dynalite 208-C200 and the microstructured hinge using ultrasonic vibration-assisted joining with support of Branson Ultrasonic Ltd. The joint between the hinge and the CFRP sheet was created by placing several individual joining points with a base area of $(10 \times 10) \mathrm{mm}^{2}$ on the sample geometry. The individual joining points were placed one after the other with a distance of about $3 \mathrm{~cm}$, centrally along the microstructured area. In order to reduce the influence of the individual joining points by setting the following joining point, a blank holder was used. No visible delamination effects occurred in the CFRP sheet. Figure 11 shows the demonstrational part consisting of the microstructured hinge and a sheet of carbon fibre-reinforced thermoplastic. The total area which has been microstructured is approximately $(30 \times 100) \mathrm{mm}^{2}$ and the dimensions of the FRP-sheet are $124 \mathrm{~mm} \times 48 \mathrm{~mm} \times 1 \mathrm{~mm}$. The manufactured demonstrational part will be integrated into a car bonnet for demonstrative purposes which is optimised for both weight and stiffness. 

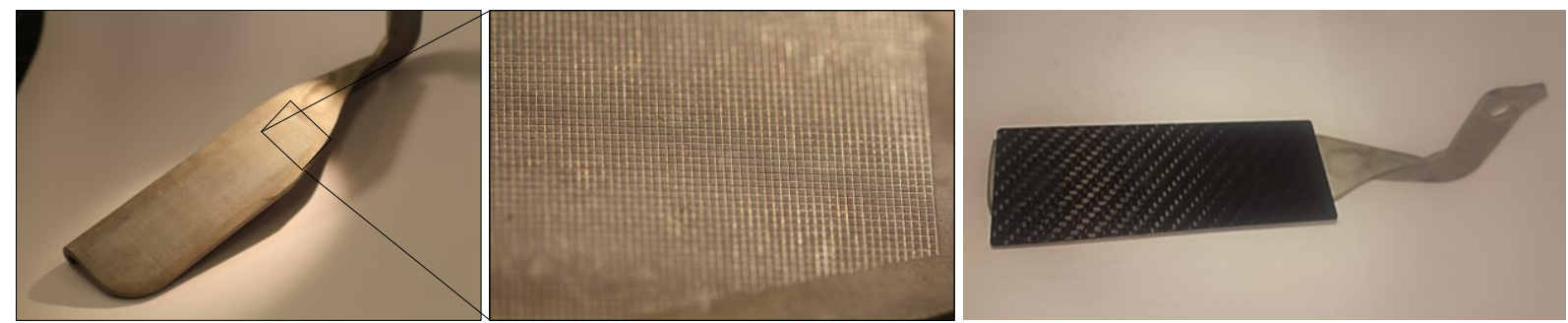

Figure 11: Overview and detailed photos of the demonstrational "bonnet hinge" from EN AW-6082 with a microstructure produced by Jet-ECM; on the left: bonnet hinge with microstructured joining area; middle: detail of the microstructured joining area; on the right: microstructured bonnet hinge joined with a fibre-reinforced thermoplastic by means of ultrasonic vibrationassisted joining

\section{Discussion and conclusion}

In this paper, electrochemical machining with continuous electrolytic-free jet (Jet-ECM) was investigated as a potential technology for the manufacturing of microstructures in joining areas in aluminium alloys. The results showed that microstructuring of metallic joining partners increases the strength of hybrid joints. By the use of ultrasonic vibration-assisted joining, it is possible to locally melt the thermoplastic matrix of the carbon fibre-reinforced plastic and to integrate the reinforcing fibres proportionally into the joint. The increase in tensile shear strength can be attributed to three effects. To begin with, an enlargement of the surface by means of microstructuring increases the proportion of the adhesive effect of the matrix material. Furthermore, a form closure joint between the microstructured EN AW-5083 sample and the CFRP is generated. Finally, integrating load bearing fibres into the connection allowed for an additional increase. In summary, the strength of hybrid composites made of the aluminium alloy EN AW-5083 and the fibre-reinforced thermoplastic Tepex® Dynalite was increased by a factor of 2.5 applying a microstructuring of the joining areas by Jet-ECM.

\section{Acknowledgment}

This work was performed within the Federal Cluster of Excellence EXC 1075 "MERGE Technologies for Multifunctional Lightweight Structures" and supported by the German Research Foundation (DFG). Financial support is gratefully acknowledged.

\section{References}

[1] Hackert-Oschätzchen, M.; Meichsner, G.; Zinecker, M.; Martin, A.; Schubert, A.: Micro machining with continuous electrolytic free jet. Precis. Eng., 36 (2012), pp. 612-619. doi: 10.1016/j.precisioneng.2012.05.003

[2] Hackert-Oschätzchen, M.; Meichsner, G.; Schubert, A.: Generating plane and microstructured surfaces applying jet electrochemical machining. In: Proceedings of fifth international symposium on electrochemical machining technology, INSECT 2009, 1 (2009). pp. 51-58.

[3] Natsu, W.; Ikeda, T.; Kunieda, M.: Generating complicated surface with electrolyte jet machining. Precis. Eng., 31 (2007), pp. 33-39. doi: 10.1016/j.precisioneng.2006.02.004

[4] Wodara, J.; Herold, H.: Ultraschallfügen und -trennen. Düsseldorf: DVS-Verlag, 2004.

[5] Flock, D.; Haberstroh, E.; Bobzin, K.; Schläfer, T.; Warda, T.; Kutschman, P.: Ultrasonic welding of hybrid metal-plastic components with flame spraying of adhesion layer, J. of Plast. Technol., 7 (5) (2011), pp. 160-176.

[6] Wagner, G.; Balle, F.; Eifler, D.: Ultrasonic metal welding of aluminium sheets to carbon fibre reinforced thermoplastic composites. Adv. Eng. Mat., 11 (2009), pp. 35-39. doi: 10.1002/adem.200800271 
[7] Krüger, S.: Ultraschallschweißen von Glasfasertextilien und Glasfaserverbundwerkstoffen mit Blechen, Techn. Univ., Lehrstuhl für Werkstoffkunde, Kaiserslautern, 2005.

[8] Schulze, R.; Jahn, S. F.; Zeidler, H.; Lindner, T.; Schubert, A.: Multi material ultrasonic joining using microstructured joining partners, In: Proc. euspen's 16th International Conference \& Exhibition, 2016, S. 511-512. 